\title{
Lieutenant Suffers Heart Attack During Fire Suppression Operations at Residential Fire and Dies Ten Days Later - Georgia
}

\section{Executive Summary}

On April 24, 2015, a 54-year-old male career lieutenant (“LT") responded to a fire in an unoccupied residential structure. The LT drove a service engine alone to the scene, and then stretched about 200 feet of uncharged 11/2-inch hoseline from Engine 200 to the structure as crewmembers arriving separately began donning self-contained breathing apparatus (SCBA). After the hoseline was charged, the LT performed exterior fire suppression for about 5 minutes when the crewmembers advanced the hoseline to the rear of the structure. As the LT returned to the front of the structure he collapsed.

On-scene crewmembers and ambulance service paramedics immediately began cardiopulmonary resuscitation (CPR) and advanced life support. A cardiac monitor revealed ventricular fibrillation; one shock was administered on-scene and one shock was administered during transport to the emergency department (ED). Inside the ED, two additional shocks were administered with return of a pulse. The LT's condition stabilized over the next hour and he was flown to a regional advanced care hospital for emergency cardiac catheterization. Despite some success opening the blocked coronary artery and 10 days in the intensive care unit, the LT remained unconscious and tests revealed anoxic brain damage. After consultation with the family, the LT was unhooked from the machines and transferred to hospice where he died 5 hours later.

The death certificate (completed by the County Coroner) and the autopsy report (completed by the State Deputy Chief Medical Examiner) both listed "myocarditis in varying stages of healing” as the cause of death with "atherosclerotic and hypertensive cardiovascular disease and diabetes mellitus" as contributing factors. The LT's myocarditis and coronary heart disease were both undiagnosed prior to this incident. These two underlying conditions set the stage for the physical stress of advancing the hoseline and performing exterior fire suppression to trigger a heart attack, which ultimately resulted in his death.

\section{Key Recommendations}

- Provide preplacement and annual medical evaluations to all fire fighters consistent with National Fire Protection Association (NFPA) 1582, Standard on Comprehensive Occupational Medical Program for Fire Departments, to identify fire fighters at increased risk for coronary heart disease (CHD)

- Perform symptom-limiting exercise stress tests (ESTs) on fire fighters at increased risk for CHD

- Ensure that fire fighters are cleared for return to duty by a physician knowledgeable about the physical demands of fire fighting, the personal protective equipment used by fire fighters, and the components of NFPA 1582 


\section{Lieutenant Suffers Heart Attack During Fire Suppression Operations at Residential Fire and Dies Ten Days Later - Georgia}

The following recommendations would not have prevented the LT's death, but NIOSH investigators include them to address general safety and health issues:

- Phase in a mandatory comprehensive wellness and fitness program for fire fighters

- Provide fire fighters with medical clearance to wear a self-contained breathing apparatus (SCBA) as part of the fire department's medical evaluation program

- Use a secondary (technological) test to confirm appropriate placement of the endotracheal tube

The National Institute for Occupational Safety and Health (NIOSH), an institute within the Centers for Disease Control and Prevention (CDC), is the federal agency responsible for conducting research and making recommendations for the prevention of work-related injury and illness. In 1998, Congress appropriated funds to NIOSH to conduct a fire fighter initiative that resulted in the NIOSH "Fire Fighter Fatality Investigation and Prevention Program" which examines line-of-duty-deaths or on duty deaths of fire fighters to assist fire departments, fire fighters, the fire service and others to prevent similar fire fighter deaths in the future. The agency does not enforce compliance with State or Federal occupational safety and health standards and does not determine fault or assign blame. Participation of fire departments and individuals in NIOSH investigations is voluntary. Under its program, NIOSH investigators interview persons with knowledge of the incident who agree to be interviewed and review available records to develop a description of the conditions and circumstances leading to the death(s). Interviewees are not asked to sign swom statements and interviews are not recorded. The agency's reports do not name the victim, the fire department or those interviewed. The NIOSH report's summary of the conditions and circumstances surrounding the fatality is intended to provide context to the agency's recommendations and is not intended to be definitive for purposes of determining any claim or benefit.

For further information, visit the program website at www.cdc.gov/niosh/fire or call toll free 1-800-CDC-INFO (1-800-232-4636). 


\section{Lieutenant Suffers Heart Attack During Fire Suppression Operations at Residential Fire and Dies Ten Days Later - Georgia}

\section{Introduction}

On April 24, 2015, a 54-year-old male career LT suffered a heart attack during fire suppression operations at a residential structure fire and died 10 days later. NIOSH was notified of the fatality on May 5, 2015, by the U.S. Fire Administration. NIOSH contacted the affected fire department on May 5, 2015, to gather additional information, and on May 11, 2015, to initiate the investigation. On May 19, 2015, a safety and occupational health specialist from the NIOSH Fire Fighter Fatality Prevention and Investigation Program conducted an on-site investigation of the incident.

During the investigation, NIOSH personnel interviewed the following people:

- Fire chief

- Training officer

- Safety officer

- Crew members

- LT’s spouse

NIOSH personnel reviewed the following documents:

- Fire department standard operating procedures

- Fire department annual report for 2014

- Witness statements

- Emergency medical service (ambulance) report

- Emergency department report

- Regional advanced care hospital records

- Death certificate

- Primary care physician records

\section{Investigation}

On April 24, 2015, the LT arrived for duty at about 0800 hours for his 24-hour shift. During most of the day, the LT performed station duties including apparatus and equipment checks and painting lines on the pavement around the fire station.

At 1731 hours, the fire department and an ambulance were dispatched to a residential fire. The LT drove Truck 2 (service engine) while a crewmember drove Engine 200 to the scene. Units arrived onscene at 1739 hours to find a single family dwelling fully involved. Four volunteer fire fighters arrived to assist. The LT, wearing turnout gear without SCBA, stretched about 200 feet of uncharged 11/2-inch hoseline from Engine 200 to the structure as crewmembers donned their SCBAs. After the hoseline was charged, the LT performed exterior fire suppression at the side of the structure for about 5 minutes before crewmembers advanced the hoseline to the rear of the structure. The LT and a crewmember walked to the front of the structure when he suddenly grabbed his chest, sat down, and then lost 


\section{Lieutenant Suffers Heart Attack During Fire Suppression Operations at Residential Fire and Dies Ten Days Later - Georgia}

consciousness (1749 hours).

Crewmembers and on-scene ambulance service paramedics began CPR and advanced life support. A cardiac monitor revealed ventricular fibrillation and one shock was administered. The LT was intubated and oxygen was administered via bag-valve-mask; an intravenous (IV) line was placed, and cardiac resuscitation medications were administered. A blood glucose analysis revealed an elevated glucose level of 236 milligrams per deciliter. The ambulance departed the scene at 1756 hours en route to the ED. One additional shock was administered en-route with no positive change in the LT's clinical condition.

The ambulance arrived at the ED at 1806 hours where two additional shocks were administered. These shocks were successful in returning a heart rhythm. At 1821 hours, the LT had a pulse of 116 beats per minute and a blood pressure of 192/103 millimeters of mercury (mmHg), but he remained unconscious on a breathing machine (ventilator). At 1836 hours, an air ambulance was called to transfer the LT to the regional hospital. At 1854 hours an electrocardiogram (EKG) was ordered; it showed an acute myocardial infarction (ST-segment elevation) within the anterior region of the heart. At 1929 hours, the air ambulance departed the local ED.

Upon arrival at the regional hospital, the LT underwent emergent cardiac catheterization which revealed a 99\% occlusion of his left anterior descending coronary artery, an 80\% occluded circumflex coronary artery, and a 70\% occluded right coronary artery. Balloon angioplasty to the proximal, mid, and distal left anterior descending artery were only partially successful (pre- post-intervention flow increased slightly). During the catheterization, an intra-aortic blood pump was placed to maintain the LT's blood pressure. At 2148 hours, the LT was transferred to the critical care unit. A subsequent echocardiogram revealed a left ventricular ejection fraction of 35-40\% with an akinetic apex and an inferior septal hypokinesis. In 10 days of life support in the critical care unit, the LT never regained consciousness. A computed tomography brain scan revealed a "diffuse loss of the white matter gray matter differentiation suspicious for diffuse brain edema or anoxo-ischemic lesion.” An electroencephalogram revealed "diffuse severe might occur with encephalopathy, dementia, or a postictal state.” Due to his poor prognosis, and after consultation with the LT's family, the LT was transferred to a hospice facility on May 4, 2015, where he passed away 5 hours later.

\section{Medical Findings}

The death certificate (completed by the County Coroner) and the autopsy report (completed by the State Deputy Chief Medical Examiner) both listed "myocarditis in varying stages of healing" as the cause of death with "atherosclerotic and hypertensive cardiovascular disease and diabetes mellitus" as contributing factors. Autopsy results can be found in Appendix A with pertinent findings being:

o Severe coronary artery disease with persistent narrowing of the left anterior descending (LAD) coronary artery with a possible thrombus despite angioplasty 10 days earlier;

o A recent evolving/healing heart attack as evidenced by red discoloration of the portion of the heart muscle supplied by the LAD distal to the blockage (thrombus). 


\section{Lieutenant Suffers Heart Attack During Fire Suppression Operations at Residential Fire and Dies Ten Days Later - Georgia}

o Histologic evidence of myocarditis (an inflammatory process in the heart muscle typically associated with a viral infection); and

o Hypertensive heart disease as evidenced by an enlarged heart with left ventricular hypertrophy.

In addition, the LT had the following pertinent medical conditions:

Diabetes Mellitus - diagnosed in 2003, poorly controlled with oral agents and then insulin in 2011. Since 2011, his hemoglobin A1c levels ranged from 8.7 to 11.6 (normal 4.0-5.6).

Hypertension - diagnosed in 2004, under fair control (Stage I) due to intermittent compliance with anti-hypertensive medications.

Hyperlipidemia - diagnosed in 2006, under fair control (LDL cholesterols 64-107) due to intermittent compliance with statin medications.

Obesity - at his last clinic visit (January 12, 2015) the LT was 69 inches tall and weighed 205 pounds, giving him a body mass index of 30.3 kilograms per meters squared [CDC 2014].

Fire Department Medical Evaluations. His only medical evaluation was his preplacement medical evaluation in 1988. No problems were identified.

\section{Fire Department}

At the time of the NIOSH investigation, the fire department consisted of two fire stations with 13 career and 25 volunteer uniformed personnel. It served 7,500 residents in a geographic area of 12 square miles. In 2014, the fire department responded to 571 incidents: 55 structure fire calls, 80 vegetation fire calls, 19 vehicle fire calls, 15 other fire calls, 67 mass mission calls, 49 alarm calls, 43 hazardous condition calls, 41 good intent calls, 36 hazardous materials calls, and 166 rescue/ emergency medical calls.

\section{Employment, Membership, Training, and Experience}

The fire department requires new career fire fighter applicants to be 18 years of age; have a valid state driver's license; and pass an oral interview prior to being offered conditional employment. The new hire must then pass a background check, a physical agility test (see Appendix B), a preplacement medical evaluation, and a drug screening. The new member is on probation for 6 months and has 1 year to complete the 120-hour Georgia Fire Fighter Standards and Training Council Core Competency Program to become a certified fire fighter. Volunteer fire fighter applicants must complete an application and pass an oral interview, a physical agility test, a background check, a preplacement medical evaluation, and a drug screening prior to being accepted. The new member has 1 year to attend the state fire training academy to become a Certified Volunteer Fire Fighter. The fire department has 4hour night drills two times per month for all members. The on-duty crew trains for 2 hours per shift and has three night drills monthly at the burn building. The LT was certified as a fire fighter III, 


\section{Lieutenant Suffers Heart Attack During Fire Suppression Operations at Residential Fire and Dies Ten Days Later - Georgia}

driver/operator, and in hazardous materials awareness. He had 27 years of fire fighting experience. He had been a LT since 1997.

\section{Preplacement and Annual Medical Evaluations/Return to Work Medical Evaluations}

The fire department requires a preplacement medical evaluation for all applicants. Components of this evaluation include the following:

- Complete medical history

- Physical examination (including vital signs - height, weight, blood pressure, pulse, and respirations)

- Vision test (acuity)

- Urine drug screen

- Urinalysis

Periodic medical evaluations are not required for members. The LT's only fire department medical evaluation was his preplacement medical evaluation in March 1988. Medical clearance to wear a respirator is not required. Members injured on duty must be evaluated by either the city-contracted physician or the member's primary care physician who forwards their determination for return-to-duty to the City human resources office.

\section{Wellness/Fitness Programs}

The fire department has a voluntary wellness/fitness program; exercise equipment is available in each of the two fire stations. A candidate physical agility test is required for all fire fighter applicants and an annual physical agility test is required for all members (see Appendix B). The LT did not participate in the fire department's voluntary wellness/fitness program. However, he was very active off-duty by mowing lawns.

\section{DISCUSSION}

\section{Sudden Cardiac Events}

In the United States, atherosclerotic coronary heart disease (CHD) is the most common risk factor for cardiac arrest and sudden cardiac death [Meyerburg and Castellanos 2008]. Risk factors for its development include age older than 45, male gender, family history of coronary artery disease, smoking, high blood pressure, high blood cholesterol, obesity/physical inactivity, and diabetes [NHLBI 2014; AHA 2015]. The LT had four modifiable CHD risk factors (high blood pressure, high blood lipids, diabetes, and obesity), and severe CHD was found on cardiac catheterization and autopsy.

The narrowing of the coronary arteries by atherosclerotic plaques occurs over many years, typically decades [Libby 2008]. However, the growth of these plaques probably occurs in a nonlinear, often abrupt fashion [Shah 1997]. Heart attacks (myocardial infarctions) typically occur with the sudden development of complete blockage (occlusion) in one or more coronary arteries that have not developed a collateral blood supply [Fuster et al. 1992]. This sudden blockage is primarily due to 


\section{Lieutenant Suffers Heart Attack During Fire Suppression Operations at Residential Fire and Dies Ten Days Later - Georgia}

blood clots (thromboses) forming on top of atherosclerotic plaques. Establishing a recent (acute) heart attack requires any of the following: characteristic EKG changes, elevated cardiac enzymes, or coronary artery thrombus. In this case, the EKG, cardiac enzymes, cardiac catheterization, and autopsy finding all confirmed a heart attack.

\section{Myocarditis}

In addition to CHD, the LT had myocarditis diagnosed at autopsy (see Appendix A). Myocarditis is an inflammation of the heart muscle, typically due to an infection, a toxin, or immune-mediated [Feldman and McNamara 2000]. The condition is considered to have three phases: acute, subacute, and chronic with the chronic phase typically presenting as dilated cardiomyopathy. The diagnosis is made by a combination of clinical, laboratory, and histologic features [Feldman and McNamara 2000]. Due to problems with sensitivity and specificity, the histologic findings should not be used alone to diagnose the condition [Cooper Jr TL, 2009]. The LT’s medical records reported no signs or symptoms consistent with any of the three phases of cardiomyopathy and did not have dilated cardiomyopathy on autopsy. While the histologic findings on autopsy were consistent with myocarditis, these findings were probably insufficient to confirm the diagnosis.

\section{Physiological Stress of Firefighting}

Epidemiologic studies have found that heavy physical exertion sometimes immediately precedes and triggers the onset of acute heart attacks and sudden cardiac death [Mittleman et al. 1993; Willich et al. 1993; Albert et al. 2000]. Sudden cardiac events in fire fighters have been associated with alarm response, fire suppression, and heavy exertion during training (including physical fitness training) [Kales et al. 2003; Kales et al. 2007; NIOSH 2007]. The LT had stretched about 200 feet of uncharged 11/2-inch hoseline, then performed exterior fire suppression. This activity expended about 9 metabolic equivalents, which is considered heavy physical activity [Gledhill and Jamnik 1992; Ainsworth et al. 2011].

\section{Occupational Medical Standards for Structural Fire Fighters}

To reduce the risk of sudden cardiac arrest or other incapacitating medical conditions among fire fighters, the National Fire Protection Association developed NFPA 1582, Standard on Comprehensive Occupational Medical Program for Fire Departments [NFPA 2013]. This voluntary industry standard provides the components of a preplacement and annual medical evaluation and medical fitness for duty criteria. The LT had two poorly controlled conditions addressed by NFPA 1582: 1) Stage II hypertension and 2) type 2 diabetes mellitus.

Hypertension. The LT fluctuated between Stage I and Stage II hypertension. NFPA 1582 suggests that members with Stage I hypertension be referred to their primary care physician to ensure that their blood pressure is controlled and to determine whether screening for end organ damage is indicated [NFPA 2013]. The LT's hypertension was diagnosed in 2004 and was intermittently controlled with medication. He did not have a complete work-up for end organ damage. The LT's most recent blood pressure readings were elevated. 


\section{Lieutenant Suffers Heart Attack During Fire Suppression Operations at Residential Fire and Dies Ten Days Later - Georgia}

NFPA considers that Stage II hypertension (systolic $\geq 160 \mathrm{mmHg}$ or diastolic $\geq 100 \mathrm{mmHg}$ ) or end organ damage (retinopathy, nephropathy, neuropathy, or vascular/cardiac complications) compromises the member's ability to safely perform essential job tasks such as the following: 1) wearing personal protective ensemble and SCBA, performing fire fighting tasks (hoseline operations, extensive crawling, lifting and carrying heavy objects, ventilating roofs or walls using power or hand tools, forcible entry, etc.), rescue operations, and other emergency response actions under stressful conditions, including working in extremely hot or cold environments for prolonged time periods; 2) wearing a fire protective ensemble that is encapsulating and insulated, which will result in significant fluid loss that frequently progresses to clinical dehydration and can elevate core temperature to levels exceeding $102.2^{\circ} \mathrm{F} ; 3$ ) wearing a personal protective ensemble and SCBA, advancing water-filled hoselines up to $2 \frac{1}{2}$ inches in diameter from fire apparatus to occupancy [approximately 150 feet], which can involve negotiating multiple flights of stairs, ladders, and other obstacles; 4) unpredictable emergency requirements for prolonged periods of extreme physical exertion without benefit of warmup, scheduled rest periods, meals, access to medication(s), or hydration; and 5) functioning as an integral component of a team, where sudden incapacitation of a member can result in mission failure or in risk of injury or death to civilians or other team members. Therefore, according to NFPA 1582, the LT’s Stage II hypertension should have resulted in work restrictions [NFPA 2013].

Diabetes Mellitus. NFPA 1582 provides guidance for fire department physicians treating diabetic fire fighters [NFPA 2013]. The standard states that fire fighters with diabetes mellitus that is controlled by insulin agents should be restricted from duty unless the member meets all of the following criteria:

(1) Has had no episodes of severe hypoglycemia (defined as requiring assistance of another) in the preceding year, with no more than one episode of severe hypoglycemia in the preceding 5 years

(2) Has achieved a stable blood glucose as evidenced by $\mathrm{HA}_{1} \mathrm{C}$ level below 8\% during the prior 3month period

(3) Has a dilated retinal exam by a qualified ophthalmologist or optometrist that shows no higher grade of diabetic retinopathy than microaneurysms

(4) Has normal renal function on the basis of a calculated creatinine clearance greater than 60 milliliters per minute and absence of proteinuria

(5) Has no autonomic or peripheral neuropathy

(6) Has normal cardiac function without evidence of myocardial ischemia on EST with imaging studies to at least 12 METs [NFPA 2013]

The LT had diabetes mellitus; and his most recent $\mathrm{HA}_{1} \mathrm{C}$ level was $11.6 \%$ in September 2014. In addition, he did not have a dilated retinal exam or an EST. Therefore, according to NFPA 1582, he should have been restricted from fire fighting duties until he lowered his $\mathrm{HA}_{1} \mathrm{C} \%$ and a dilated retinal exam and an EST were conducted. 


\section{Lieutenant Suffers Heart Attack During Fire Suppression Operations at Residential Fire and Dies Ten Days Later - Georgia}

\section{Exercise Stress Tests}

Recommendations on whether to screen asymptomatic individuals for CHD with EST are varied. The following paragraphs summarize the positions of widely recognized organizations on this topic.

\section{NFPA}

NFPA 1582, a voluntary industry standard, recommends an EST be performed "as clinically indicated by history or symptoms" and refers the reader to Appendix A [NFPA 2013]. Items in Appendix A are not standard requirements, but are provided for "informational purposes only." Appendix A recommends using submaximal (85\% of predicted heart rate) ESTs as a screening tool to evaluate a fire fighter's aerobic capacity. Maximal (i.e., symptom-limiting) ESTs with imaging should be used for fire fighters with the following conditions:

- abnormal screening submaximal tests

- cardiac symptoms

- known CHD

- one or more risk factors for CHD (in men older than 45 and women older than 55)

Risk factors are defined as hypercholesterolemia (total cholesterol greater than 240 milligrams per deciliter), hypertension (diastolic blood pressure greater than $90 \mathrm{~mm}$ of mercury), smoking, diabetes mellitus, or family history of premature CHD (heart attack or sudden cardiac death in a first-degree relative less than 60 years old). Given the LT's age, CHD risk factors, and Framingham Risk Score, NFPA 1582 would have recommended a symptom-limiting EST.

\section{American College of Cardiology/American Heart Association (ACC/AHA)}

The ACC/AHA has also published testing guidelines [Gibbons et al. 2002]. The ACC/AHA guidelines state that the evidence to conduct ESTs in asymptomatic individuals with diabetes mellitus is "in favor of” (Class IIa) for persons who plan to start vigorous exercise. Given the LT's public safety position and his diabetes mellitus, the ACC/AHA criteria suggest an EST would have been appropriate.

\section{U.S. Department of Transportation}

The U.S. Department of Transportation provides guidance for those seeking medical certification for a commercial driver's license. An expert medical panel recommended exercise tolerance tests for asymptomatic "high risk" drivers [Blumenthal et al. 2007]. The panel defines high risk drivers as those with any of the following:

- diabetes mellitus

- peripheral vascular disease

- age 45 and above with multiple risk factors for CHD

- Framingham risk score predicting a 20\% CHD event risk over the next 10 years

The LT was over age 45, had diabetes mellitus, and had multiple risk factors for CHD. Despite his last Framingham risk score of $18.9 \%$, the U.S. Department of Transportation would have recommended an EST for a commercial truck driver with a similar profile [ACC 2014]. 


\section{Lieutenant Suffers Heart Attack During Fire Suppression Operations at Residential Fire and Dies Ten Days Later - Georgia}

\section{U.S. Preventive Services Task Force (USPSTF)}

The U.S. Preventive Services Task Force (USPSTF) does not recommend ESTs for asymptomatic individuals at low risk for CHD events. For individuals at increased risk for CHD events, the USPSTF found "insufficient evidence to recommend for or against routine screening with EKG, exercise tolerance test, or electron beam computerized tomography scanning...." Rather, they recommend the diagnosis and treatment of modifiable risk factors (hypertension, high cholesterol, smoking, and diabetes) [USPSTF 2004]. The USPSTF does note that "For people in certain occupations, such as pilots, and heavy equipment operators (for whom sudden incapacitation or sudden death may endanger the safety of others), consideration other than the health benefit to the individual patient may influence the decision to screen for coronary heart disease."

In summary, the LT had multiple medical conditions that should have resulted in restricted duty. In addition, he should have had an EST to screen for CHD. If an EST had been conducted, perhaps his CHD would have been identified leading to further evaluation and treatment.

\section{Recommendations}

Recommendation \#1: Provide preplacement and annual medical evaluations to all fire fighters in accordance with NFPA 1582, Standard on Comprehensive Occupational Medical Program for Fire Departments, to identify fire fighters at increased risk for $\mathrm{CHD}$.

Discussion: We applaud the fire department for providing preplacement medical evaluations. However, the fire department's medical program could be strengthened by expanding the components of the preplacement evaluations and offering annual medical evaluations. Guidance regarding the content and frequency of these medical evaluations can be found in NFPA 1582 and in the International Association of Fire Fighters (IAFF)/International Association of Fire Chiefs (IAFC) Fire Service Joint Labor Management Wellness/Fitness Initiative [IAFF, IAFC 2008; NFPA 2013]. These evaluations are performed to determine fire fighters' medical ability to perform duties without presenting a significant risk to the safety and health of themselves or others. Following this recommendation will require significant resources and may be particularly difficult for smaller fire departments to implement. The fire department is not legally required to follow the NFPA standard or the IAFF/IAFC guideline.

To overcome the financial obstacle of medical evaluations, the fire department could urge current members to get annual medical clearances from their private physicians through insurance, another job, or paid for by the fire department, city, or state. Sharing the financial responsibility for these evaluations between fire fighters, the fire department, the city, and the state may reduce the negative financial impact on recruiting and retaining needed fire fighters.

\section{Recommendation \#2: Perform symptom-limiting ESTs on fire fighters at increased risk for CHD.}

Discussion: Firefighters with multiple or severe CHD risk factors, or a Framingham risk score $>10 \%$, are at increased risk of a sudden cardiac event [AHA 2014; NHLBI 2014b]. The fire department does 


\section{Lieutenant Suffers Heart Attack During Fire Suppression Operations at Residential Fire and Dies Ten Days Later - Georgia}

not screen members for CHD risk factors, and does not conduct aerobic capacity tests or ESTs to determine whether fire fighters are at increased risk for a sudden cardiac event.

\section{Recommendation \#3: Ensure that fire fighters are cleared for return to duty by a physician knowledgeable about the physical demands of fire fighting, the personal protective equipment used by fire fighters, and the various components of NFPA 1582.}

Discussion: According to NFPA 1582, the fire department should have an officially designated physician who is responsible for guiding, directing, and advising the members with regard to their health, fitness, and suitability for duty [NFPA 2013]. The physician should review job descriptions and essential job tasks required for all fire department positions to understand the physiological and psychological demands of fire fighters and the environmental conditions under which they must perform, as well as the personal protective equipment they must wear during various types of emergency operations. The fire department uses the member's personal physician or the Citycontracted physician to clear fire fighters who miss work due to injury/illness. Personal physicians may be unaware of the hazardous and physical demands of structural fire fighting and the guidance provided by NFPA 1582.

The following recommendations would not have prevented the LT's death, but NIOSH investigators include them to address general safety and health issues:

\section{Recommendation \#4: Phase in a mandatory comprehensive wellness and fitness program for fire fighters.}

Discussion: Guidance for fire department wellness/fitness programs to reduce risk factors for cardiovascular disease and improve cardiovascular capacity is found in NFPA 1583, Standard on Health-Related Fitness Programs for Fire Fighters, the IAFF/IAFC Fire Service Joint Labor Management Wellness/Fitness Initiative, and in Firefighter Fitness: A Health and Wellness Guide [IAFF, IAFC 2008; NFPA 2008; Schneider 2010]. Worksite health promotion programs have been shown to be cost effective by increasing productivity, reducing absenteeism, and reducing the number of work-related injuries and lost work days [Chapman 2005; Mills et al. 2007; Pelletier 2009; Baicker et al. 2010]. Fire service health promotion programs have been shown to reduce CAD risk factors and improve fitness levels, with mandatory programs showing the most benefit [Dempsey et al. 2002; Womack et al. 2005; Blevins et al. 2006]. A study conducted by the Oregon Health and Science University reported a savings of more than \$1 million for each of four large fire departments implementing the IAFF/IAFC wellness/fitness program compared to four large fire departments not implementing a program. These savings were primarily due to a reduction of occupational injury/illness claims with additional savings expected from reduced future nonoccupational healthcare costs [Kuehl 2013].

The fire department offers a voluntary wellness/fitness program with exercise equipment in the fire stations. NIOSH recommends a formal, mandatory wellness/fitness program to ensure all members 


\section{Lieutenant Suffers Heart Attack During Fire Suppression Operations at Residential Fire and Dies Ten Days Later - Georgia}

receive the benefits of a health promotion program. Installing similar exercise equipment in each fire station would allow consistent exercise regimens for members who transfer from station to station or work overtime at another station.

Recommendation \#5: Provide fire fighters with medical clearance to wear SCBA as part of the fire department's medical evaluation program.

Discussion: The Occupational Safety and Health Administration (OSHA) Revised Respiratory Protection Standard requires employers to provide medical evaluations and clearance for employees using respiratory protection [29 CFR 1910.134]. These clearance evaluations are required for private industry employees and only for public employees in states operating OSHA-approved state plans. Because Georgia does not operate a state OSHA plan [OSHA 2015], the fire department is not required to provide medical evaluations for employees using respirators. However, we recommend voluntary compliance with this recommendation to improve fire fighter health and safety.

Recommendation \#6: Use a secondary (technological) test to confirm appropriate placement of the endotracheal tube.

Discussion: To reduce the risk of improper intubation, the AHA and the International Liaison Committee on Resuscitation published recommendations in the "Guidelines 2000 for Cardiopulmonary Resuscitation and Emergency Cardiovascular Care” [AHA 2000]. These guidelines recommend confirming tube placement by primary and secondary methods. Primary confirmation is the five-point auscultation: left and right anterior chest, left and right midaxillary, and over the stomach. Secondary confirmation requires a technology test, either an end-tidal carbon dioxide detector or an esophageal detector device. In this incident, secondary confirmation was not performed until after the LT was in the ED. Although this issue did not contribute to the LT's death, we state it here to help ensure that future advanced life support resuscitation efforts follow AHA guidelines.

\section{References}

ACC [2014]. ASCVD risk estimator. Washington, D.C.: American College of Cardiology. [http://tools.acc.org/ASCVD-Risk-Estimator/]. Date accessed: July 2015

AHA [2000]. Advanced cardiovascular life support: section 3: adjuncts for oxygenation, ventilation, and airway control. Circ 102(8)(Suppl):I-95-I-104.

AHA [2014]. Understand your risk for arrhythmia. Dallas, TX: American Heart Association. [http://www.heart.org/HEARTORG/Conditions/Arrhythmia/UnderstandYourRiskforArrhythmia/Unde rstand-Your-Risk-for-Arrhythmia_UCM_002024_Article.jsp]. Date accessed: July 2015.

AHA [2015]. Understand your risk of heart attack. Dallas, TX: American Heart Association. [http://www.heart.org/HEARTORG/Conditions/HeartAttack/UnderstandYourRiskofHeartAttack/Unde rstand-Your-Risk-of-Heart-Attack_UCM_002040_Article.jsp]. Date accessed: July 2015. 


\section{Lieutenant Suffers Heart Attack During Fire Suppression Operations at Residential Fire and Dies Ten Days Later - Georgia}

Ainsworth BE, Haskell WL, Herrmann SD, Meckes N, Bassett DR Jr, Tudor-Locke C, Greer JL, Vezina J, Whitt-Glover MC, Leon AS [2011]. Compendium of physical activities: a second update of codes and MET values. Med Sci Sports Exerc 43(8):1575-1581.

Albert CM, Mittleman MA, Chae CU, Lee IM, Hennekens CH, Manson JE [2000]. Triggering of sudden death from cardiac causes by vigorous exertion. N Engl J Med 343(19):1355-1361.

Baicker K, Cutler D, Song Z [2010]. Workplace wellness programs can generate savings. Health Affairs 29(2):1-8.

Blevins JS, Bounds R, Armstrong E, Coast JR [2006]. Health and fitness programming for fire fighters: does it produce results? Med Sci Sports Exerc 38(5):S454.

Blumenthal RS, Epstein AE, Kerber RE [2007]. Expert panel recommendations. Cardiovascular disease and commercial motor vehicle driver safety. [http://www.mrb.fmcsa.dot.gov/documents/CVD_Commentary.pdf]. Date accessed: July 2015.

CDC (Centers for Disease Control and Prevention) [2014]. Assessing your weight. [http://www.cdc.gov/healthyweight/assessing/index.html]. Date accessed: July 2015.

CFR. Code of Federal Regulations. Washington, DC: U.S. Government Printing Office, Office of the Federal Register.

Chapman LS [2005]. Meta-evaluation of worksite health promotion economic return studies: 2005 update. Am Health Promot 19(6):1-11.

Cooper Jr TL [2009]. Myocarditis. N Engl J Med 360(15):1526-1538.

Dempsey WL, Stevens SR, Snell CR [2002]. Changes in physical performance and medical measures following a mandatory firefighter wellness program. Med Sci Sports Exerc 34(5):S258.

Feldman AM, McNamara D [2000]. Myocarditis. N Eng J Med 343(19):1388-1398.

Fuster V, Badimon L, Badimon JJ, Chesebro JH [1992]. The pathogenesis of coronary artery disease and the acute coronary syndromes. N Engl J Med 326(4):242-250.

Gibbons RJ, Balady GJ, Bricker JT, Chaitman BR, Fletcher GF, Froelicher VF, Mark DB, McCallister BD, Mooss AN, O'Reilly MG, Winters WL Jr., Antman EM, Alpert JS, Faxon DP, Fuster V, Gregoratos G, Hiratzka LF, Jacobs AK, Russell RO, Smith SC Jr [2002]. ACC/AHA 2002 guideline update for exercise testing: a report of the American College of Cardiology/ American Heart Association Task Force on Practice Guidelines. Circulation 106(14):1883-1892. 


\section{Lieutenant Suffers Heart Attack During Fire Suppression Operations at Residential Fire and Dies Ten Days Later - Georgia}

Gledhill N, Jamnik VK [1992]. Characterization of the physical demands of firefighting. Can J Spt Sci 17(3):207-213.

IAFF, IAFC [2008]. The fire service joint labor management wellness/fitness initiative. 3rd ed. Washington, DC: International Association of Fire Fighters, International Association of Fire Chiefs.

Kales SN, Soteriades ES, Christoudias SG, Christiani DC [2003]. Firefighters and on-duty deaths from coronary heart disease: a case control study. Environ health: a global access science source. 2:14. [http://www.ehjournal.net/content/2/1/14]. Date accessed: July 2015.

Kales SN, Soteriades ES, Christophi CA, Christiani DC [2007]. Emergency duties and deaths from heart disease among fire fighters in the United States. N Engl J Med 356(12):1207-1215.

Kuehl KS, Elliot DL, Goldberg L, Moe EL, Perrier E, Smith J [2013]. Economic benefit of the PHLAME wellness programme on firefighter injury. Occup Med 63(3):203-209.

Libby P [2008]. The pathogenesis, prevention, and treatment of atherosclerosis. In: Fauci AS, Braunwald E, Kasper DL, Hauser SL, Longo DL, Jameson JL, Loscalzo J, eds. Harrison's principles of internal medicine. 17th ed. New York: McGraw-Hill, pp. 1501-1509.

Meyerburg RJ, Castellanos A [2008]. Cardiovascular collapse, cardiac arrest, and sudden cardiac death. In: Fauci AS, Braunwald E, Kasper DL, Hauser SL, Longo DL, Jameson JL, Loscalzo J, eds. Harrison’s principles of internal medicine. 17th ed. New York: McGraw-Hill, pp. 1707-1713.

Mills PR, Kessler RC, Cooper J, Sullivan S [2007]. Impact of a health promotion program on employee health risks and work productivity. Am J Health Promot 22(1):45-53.

Mittleman MA, Maclure M, Tofler GH, Sherwood JB, Goldberg RJ, Muller JE [1993]. Triggering of acute myocardial infarction by heavy physical exertion. N Engl J Med 329(23):1677-1683.

NFPA [2008]. Standard on health-related fitness programs for fire fighters. Quincy, MA: National Fire Protection Association. NFPA 1583.

NFPA [2013]. Standard on comprehensive occupational medical program for fire departments. Quincy, MA: National Fire Protection Association. NFPA 1582.

NHLBI [2014]. Who is at risk for coronary artery disease? National Heart, Lung, and Blood Institute. [http://www.nhlbi.nih.gov/health/health-topics/topics/cad/atrisk.html]. Date accessed: July 2015.

NIOSH [2007]. NIOSH alert: preventing fire fighter fatalities due to heart attacks and other sudden cardiovascular events. [http://www.cdc.gov/niosh/docs/2007-133/]. Cincinnati, OH: U.S. Department 


\section{Lieutenant Suffers Heart Attack During Fire Suppression Operations at Residential Fire and Dies Ten Days Later - Georgia}

of Health and Human Services, Centers for Disease Control and Prevention, National Institute for Occupational Safety and Health, DHHS (NIOSH) Publication No. 2007-133.

OSHA (Occupational Safety and Health Administration) [2015]. State occupational safety and health plans. [http://www.osha.gov/dcsp/osp/index.html]. Date accessed: July 2015.

Pelletier KR [2009]. A review and analysis of the clinical and cost-effectiveness studies of comprehensive health promotion and disease management programs at the worksite: update VII 20042008. J Occup Environ Med 51(7):822-837.

Schneider EL [2010]. Firefighter fitness: a health and wellness guide. New York: Nova Science Publishers.

Shah PK [1997]. Plaque disruption and coronary thrombosis: new insight into pathogenesis and prevention. Clin Cardiol 20(11 Suppl2):II-38-44.

USPSTF [2004]. U.S. Prevention Services Task Force. Screening for coronary heart disease: Recommendation Statement. Ann Intern Med 140(7):569-572.

Willich SN, Lewis M, Lowel H, Arntz HR, Schubert F, Schroder R [1993]. Physical exertion as a trigger of acute myocardial infarction. N Engl J Med 329(23):1684-1690.

Womack JW, Humbarger CD, Green JS, Crouse SF [2005]. Coronary artery disease risk factors in firefighters: effectiveness of a one-year voluntary health and wellness program. Med Sci Sports Exerc 37(5):S385.

\section{Investigator Information}

This incident was investigated by the NIOSH Fire Fighter Fatality Investigation and Prevention Program, Cardiovascular Disease Component in Cincinnati, Ohio. Mr. Tommy Baldwin (MS) led the investigation and co-authored the report. Mr. Baldwin is a Safety and Occupational Health Specialist, a National Association of Fire Investigators (NAFI) Certified Fire and Explosion Investigator, an International Fire Service Accreditation Congress (IFSAC) Certified Fire Officer I, and a former Fire Chief and Emergency Medical Technician. Dr. Thomas Hales (MD, MPH) provided medical consultation and co-authored the report. Dr. Hales is a member of the NFPA Technical Committee on Occupational Safety and Health, and Vice-Chair of the Public Safety Medicine Section of the American College of Occupational and Environmental Medicine (ACOEM).

\section{Disclaimer}

Mention of any company or product does not constitute endorsement by the National Institute for Occupational Safety and Health (NIOSH). In addition, citations to Web sites external to NIOSH do not 


\section{Lieutenant Suffers Heart Attack During Fire Suppression Operations at} Residential Fire and Dies Ten Days Later - Georgia

constitute NIOSH endorsement of the sponsoring organizations or their programs or products. Furthermore, NIOSH is not responsible for the content of these Web sites. 


\section{Lieutenant Suffers Heart Attack During Fire Suppression Operations at Residential Fire and Dies Ten Days Later - Georgia}

\section{Appendix A Autopsy Findings}

- Coronary artery atherosclerosis

o Left anterior descending (LAD) coronary artery

$>$ Proximal: $90 \%$ narrowing

$>$ Mid: 50\% narrowing with "questionable" thrombus

$>$ Distal: 50-90\% patchy narrowing

o Left circumflex coronary artery - slight narrowing throughout

o Right coronary artery - 60\% narrowing in the mid-section

o Red discoloration of the interventricular septum to the anterior wall of the left ventricle

$>$ [changes consistent with an evolving/healing myocardial infarction (heart attack) along the LAD coronary artery]

- Myocarditis

o Histologic (microscopic) examination of two sections of the heart muscle showed "intermixed areas of mononuclear cells, myocyte necrosis, granulation tissue, and fibrosis throughout”; a finding consistent, but not diagnostic for myocarditis [Feldman and McNamara 2000].

- Hypertensive heart disease

o Cardiomegaly (heart weighed 560 grams [g]; predicted normal weight is $349 \mathrm{~g}$ [ranges between $265 \mathrm{~g}$ and $461 \mathrm{~g}$ as a function of sex, age, and body weight]) [Silver and Silver 2001]

o Left ventricular hypertrophy

- Left ventricle thickened ( 2.0 centimeter $[\mathrm{cm}]$ )

o Normal at autopsy is 0.76-0.88 cm [Colucci and Braunwald 1997]

o Histologic - myocyte hypertrophy

- Normal cardiac valves

- No evidence of a pulmonary embolus (blood clot in the lung arteries)

- Negative blood test for drugs and alcohol

\section{REFERENCES}

Colucci WS, Braunwald E [1997]. Pathophysiology of heart failure. In: Braunwald, ed. Heart disease. 5th ed. Philadelphia, PA: W.B. Saunders Company, p. 401.

Silver MM, Silver MD [2001]. Examination of the heart and of cardiovascular specimens in surgical pathology. In: Silver MD, Gotlieb AI, Schoen FJ, eds. Cardiovascular pathology. 3rd ed. Philadelphia, PA: Churchill Livingstone, pp. 8-9.

Feldman AM, McNamara D [2000]. Myocarditis. N Eng J Med 343(19):1388-1398. 


\section{Lieutenant Suffers Heart Attack During Fire Suppression Operations at Residential Fire and Dies Ten Days Later - Georgia}

\section{Appendix B \\ Physical Agility Tests}

The physical agility tests consist of the following components:

- Kaiser sled: strike with sledgehammer until the sled stops

- Advance the charged 100-foot 21/2-inch hoseline to its end

- Drag the 165 pound manikin 50-feet

- Ladder lifts using the 24-foot extension ladder and the 12-foot roof ladder 